EGU21-16442

https://doi.org/10.5194/egusphere-egu21-16442

EGU General Assembly 2021

(c) Author(s) 2021. This work is distributed under

the Creative Commons Attribution 4.0 License.

\title{
Fracture network analysis for carbon mineralization in basalts of the Oligocene Jizan volcanics, Saudi Arabia
}

\author{
Murtadha Al Malallah ${ }^{1}$, Jakub Fedorik ${ }^{1}$, Giacomo Losi ${ }^{1}$, Yuri Panara ${ }^{2}$, Niccolo Menegoni ${ }^{2}$, \\ Abdulkader Alafifi ${ }^{1}$, and Hussein Hoteit $^{1}$ \\ ${ }^{1}$ Ali I. Al-Naimi Petroleum Engineering Research Center (ANPERC), King Abdullah University of Science and Technology \\ (KAUST), Saudi Arabia \\ ${ }^{2}$ Department of Earth and Environmental Sciences, University of Pavia, Italy
}

This study aims to characterize fracture permeability in altered Oligocene-Early Miocene basalts of the Jizan Group, which accumulated in half grabens during the continental rift stage of Red Sea evolution. Unlike fresh basalts, the Jizan Group was affected by low temperature hydrothermal metamorphism, which plugged the original matrix porosity in vesicles, breccias, and interflow layers with alteration minerals. On the other hand, the basalts are pervasively shattered by open closely spaced fractures in several directions. Characterization of these fractures is essential to reducing the fracture permeability uncertainty for mineral carbonation by the dissolved $\mathrm{CO} 2$ process such as Carbfix.

Conventional measurements of fracture orientations and densities were initially taken at outcrops of the Jizan Group to characterize the fracture network. Photogrammetry of drone images covering larger areas were then used to create 3D models of the outcrops using Agisoft Metashape, which were analyzed for fracture geometries using Cloud Compare. The automated analysis of fracture orientations and densities compared well with conventional manual measurements. This gives confidence in semi-automated dronebased fracture characterization techniques in 3D, which are faster and less labor intensive, especially for characterization of large and difficult to reach outcrops.

Our fracture characterization will be used to construct 3D fracture permeability models of the Jizan Group for combined physical and chemical simulation of injection of dissolved $\mathrm{CO} 2$ from industrial sources into basalts. This will provide essential parameters to mitigate geological risks and to determine depth, spacing, and injection rates in $\mathrm{CO} 2$ disposal wells. 